\title{
Development of an Ontology-Based Knowledge Network by Interconnecting Soil/Water Concepts/Properties, Derived from Standards Methods and Published Scientific References Outlining Infiltration/Percolation Process of Contaminated Water
}

\author{
Stephanos D. V. Giakoumatos, Anastasios K. T. Gkionakis \\ School of Maritime and Industrial Studies, University of Piraeus, Piraeus, Greece \\ Email: sgiakoum@webmail.unipi.gr, sgiakou@hotmail.com, tgkion@gmail.com
}

How to cite this paper: Giakoumatos, S. D. V., \& Gkionakis, A. K. T. (2021). Development of an Ontology-Based Knowledge Network by Interconnecting Soil/Water Concepts/Properties, Derived from Standards Methods and Published Scientific References Outlining Infiltration/Percolation Process of Contaminated Water. Journal of Geoscience and Environment Protection, 9, 25-52.

https://doi.org/10.4236/gep.2021.91003

Received: December 1, 2020

Accepted: January 15, 2021

Published: January 18, 2021

Copyright $\odot 2021$ by author(s) and Scientific Research Publishing Inc. This work is licensed under the Creative Commons Attribution International License (CC BY 4.0).

http://creativecommons.org/licenses/by/4.0/

\section{(c) (i) Open Access}

\begin{abstract}
The present work deals with the development of an Ontology-Based Knowledge Network of soil/water physicochemical \& biological properties (soil/water concepts), derived from ASTM Standard Methods $\left(\mathrm{ASTM}_{i, n}\right)$ and relevant scientific/applicable references (published papers $-\mathrm{PP}_{i, n}$ ) to fill up/bridge the gap of the information science between cited Standards and infiltration discipline conceptual vocabulary providing accordingly a dedicated/internal Knowledge Base (KB). This attempt constitutes an innovative approach, since it is based on externalizing domain knowledge in the form of Ontology-Based Knowledge Networks, incorporating standardized methodology in soil engineering. The ontology soil/water concepts (semantics) of the developed network correspond to soil/water physicochemical \& biological properties, classified in seven different generations that are distinguished/located in infiltration/percolation process of contaminated water through soil porous media. The interconnections with arcs between corresponding concepts/properties among the consecutive generations are defined by the relationship of dependent and independent variables. All these interconnections are documented according to the below three ways: 1) dependent and independent variables interconnected by using the logical operator "depends on" quoting existent explicit functions and equations; 2) dependent and independent variables interconnected by using the logical operator "depends on" quoting produced implicit functions, according to Rayleigh's method of indices; 3) dependent and independent variables interconnected by using the logical operator " $r e$ -
\end{abstract}


lated to" based on a logical dependence among the examined nodes-conceptsvariables. The aforementioned approach provides significant advantages to semantic web developers and web users by means of prompt knowledge navigation, tracking, retrieval and usage.

\section{Keywords}

Infiltration, Percolation, ASTM Standards, Soil/Water Contamination, Knowledge Base, Ontology Network, Semantics, Porous Media

\section{Introduction}

A Knowledge Base (KB) in knowledge engineering is a commonly accepted information structure over a discipline that combined with artificial intelligence and expert systems, where information can be easily retrieved in a rapid way and deployed in numerous applications, outlining the relationship with the software engineering, information integration and knowledge management (Studer et al., 1998). KBs form ontological mappings (Ontologies) by employing concepts (semantics) and rigid internal relationships amid its network corpus. Clearly defined concepts (conceptualization-explicitly or implicitly), shared (controlled) vocabulary and leveled up/down generations/classes (taxonomies) have to be built up inconsequential hierarchies (Genesereth \& Nilsson, 1987; Gruber, 1995; Guarino, 1995; Uschold \& Grüninger, 1996; Borst, 1997; Roche, 2003) to support such a structure.

Ontology-Based Knowledge Networks gradually are being applied to a vast range of disciplines, such as in soil science, by describing soil properties, processing and their interaction (Du et al., 2016; Heeptaisong \& Srivihok, 2010). Ontologies as a formal description of knowledge set, with suitably placed concepts within a domain strictly bound by well-defined relationships are applied in artificial intelligence in order to provide to all users an interaction framework with various application systems i.e. communication models between $(\mathrm{KB})$ users and machines (Weng \& Chang, 2008).

In soil science, pollutant's fate via infiltration/percolation is considered to be a multi-stage processing and undoubtedly a major concern in industrial ecology. Precipitated water runoffs could arise contamination problems on account of their penetration from humic topsoil to lower surface layers. Mikkelsen et al. (1997) presented a case of heavy traffic roads. Soil crust rehabilitation in the aftermath of a pollution incident, could be remarkably aided by already building up ontological structures dedicated to infiltration phenomena applied to various accidental cases (Du \& Cohn, 2016).

Infiltration is approached as a complex both biological \& physicochemical process during which an aquatic solution (potentially contaminated with insoluble/dispersed particles or micelles), penetrates the ground under the gravity force and/or the capillary action. The partial sub-processes which are taking 
place until the infiltration water reaches the groundwater table are, inter alia, common filtration, chemical reaction (depending on the layers of sedimentary rock/soil the water is passing through), biochemical conversion, sedimentation, coagulation, flocculation (Lassabatere et al., 2010).

In general, the infiltration rate depends mainly on 1) ground surface loading with (waste) water; 2) the soil porosity; and 3) the vegetation coverage. An introspection reveals interdependences of numerous parameters among others, type, bulk density and texture of the soil, canopy coverage and topsoil biomass production (Wang et al., 2017; Patle et al., 2018; Wood et al., 1987; Tejedor et al., 2013). The given physicochemical parameters are of variant importance/gravity in terms of inducing the evolution of the ongoing phenomenon.

In the present paper, an Ontology-Based Knowledge Network is developed of soil/water physicochemical \& biological properties (soil/water concepts), derived from ASTM standards and published scientific references in order to describe the infiltration/percolation process of contaminated water. The developed/proposed Ontology-Based Knowledge Network can be adopted as a tool for the semantic representation of infiltration/percolation process of contamination water through soil structure and porous media.

\section{Methodology}

In this section, a comprehensive Ontology-Based Knowledge Network design and construction is described/summarized by the below presented steps.

1) Determination of the initial ontology concept.

2) Determination and proper selection of other sub-concepts, which could be fitted in the ontology network, and correspond to soil/water physicochemical \& biological properties.

3) Identification of soil/water physicochemical \& biological properties through an extensive research of ASTM Standards and scientific published references.

4) Documentation of three possible ways that could justify the interconnections between all the ontology sub-concepts of our interest and relevant soil/water physicochemical \& biological properties.

As regards the first step, the "infiltration rate" of contaminated water in the soil (porous medium), it was established as the initial conceptual property of our ontology network. Interconnection of the afore-mentioned properties is achieved by adopting a framework of concepts interrelated with soil/water properties and partial sub-processes which are taking place during the process.

The infiltration rate could be measured and monitored by well-established techniques fully described by standard methods and practices recommended by a widely recognized standardization organization such as the American Society for Testing \& Material (ASTM) and relative scientific published papers. This is indispensable for obtaining results comparable with the ones obtained in similar experimental models, under similar conditions, since some of these observations are obtained with more precise measurements that are described through stan- 
dardized methods i.e. ASTM standards and scientific published papers.

According to the structure of the network, all the nodes/concepts/physicochemical and biological properties are interconnected by using the principles set by dependent and independent variables. This set of dependent and independent variables justified and documented by three possible ways, as they are describing below:

1) Dependent and independent variables interconnected by using the logical operator "depends on" quoting existent explicit functions and equations;

2) Dependent and independent variables interconnected by using the logical operator "depends on" quoting produced implicit functions, by implementing Rayleigh's method of indices;

3) Dependent and independent variables interconnected by using the logical operator "related to" based on a logical dependence between the examined nodes-concepts-variables.

The last Rayleigh's method of indices is based on the fundamental principle of dimensional homogeneity of physical variables involved in this problem. The dependent variable is identified and expressed as a product of all the independent variables raised to an unknown integer exponent. Equating the indices of $n$ fundamental dimensions of the variables involved, $n$ independent equations are obtained. Finally, these $n$ equations are solved to obtain the dimensionless groups.

\section{Implementation}

Under the form of the directed/developed ontology network, shown in Figure A2 of the Appendix, it can be easily supported by a computer program through several ready-to-use packages already available in the market. All these nodes/ concepts/properties are represented by ASTM standards and scientific published papers in an integrated Ontology-Based Knowledge Network, Figure A1 of the Appendix, a part of which is shown in Figure 1 of the current page.

Each node of ASTM standard and published paper has a set of references to other ASTM standards or/and published papers. All the nodes of scientific published papers and ASTM standards are symbolized as $\mathrm{PP}_{i, n}$ and $\mathrm{ASTM}_{i, n}$ respectively, where $i$ denotes the generation number, and $\mathrm{n}$ denotes the member number of each generation. Starting from a certain ASTM standard, related with the topic under consideration (e.g. "Infiltration Rate Determination Using Double-Ring Infiltrometer with Sealed-Inner Ring", according to D5093-15 ASTM Standard Test Method, in the case of the present work), we may represent it as well as its references with points or vertices or nodes interconnected with arcs directed from the initial standard to its references. These references are all members of the first generation with the initial standard as unique parent. Each member of the first generation has other referenced ASTM standards or/and published papers of its own, creating a second generation, and so forth until the seventh generation is achieved in our case. Evidently, the initial standard as well as any 


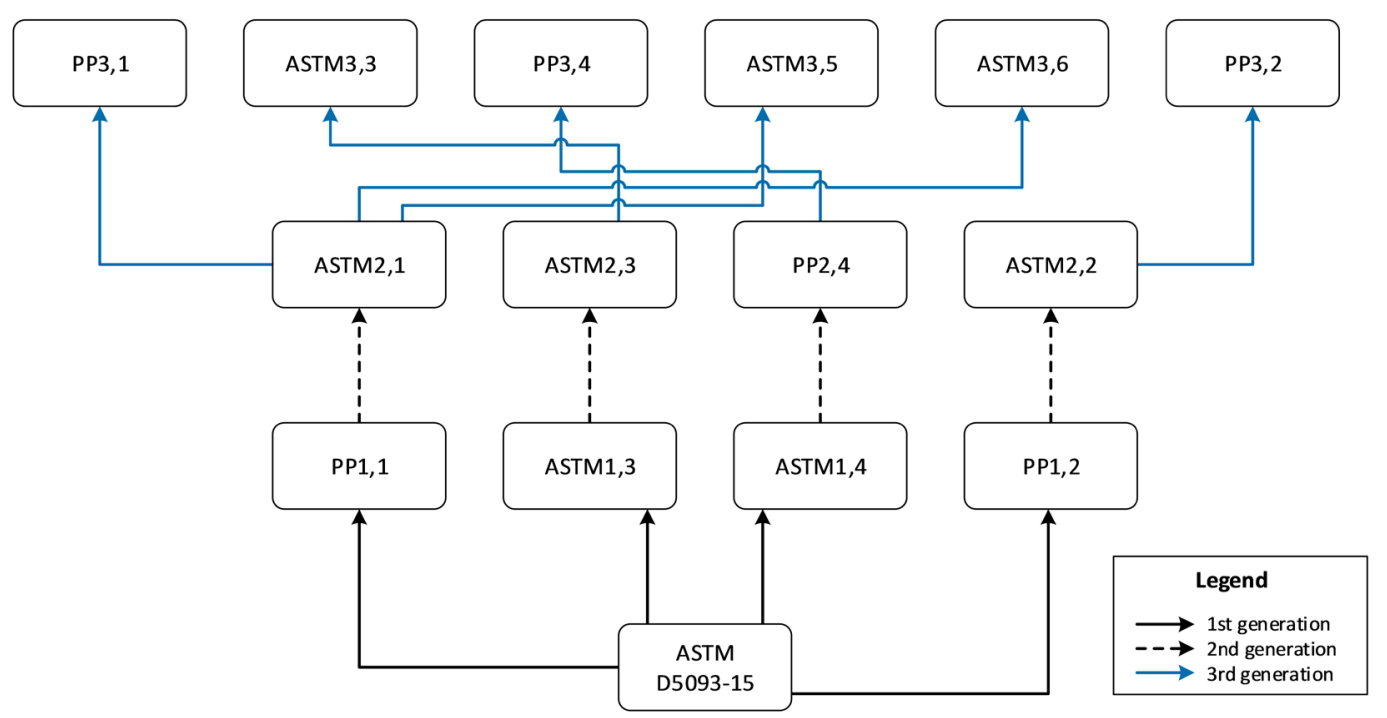

Figure 1. Part of the ontology-based knowledge network of ASTM standards and scientific published papers for estimating the infiltration rate of contaminated water.

member of the $i$ generation may be a member of one or more generations i.e. a member of the $i(i=0,1,2, \ldots)$ generation may also appear as a member of the $j$ generation, provided that $j \geq i+2$.

Values, indicating dependence of applying a standard or/and published paper (especially of carrying out a standard test) on the previous application of another standard or/and published paper of the next generation, are assigned to each arc, so that a network is obtained from the directed multi-graph. These values vary from zero, indicating no dependence whatsoever, up to one, indicating full dependence (e.g. Table $1 \&$ Table 2). Dependence concerning only knowledge that must be acquired for carrying out successfully a standard test is considered to be zero. Dependence of carrying out a standard test on the provision of a material with certain specifications varies from one to zero.

In the application example of current page, the selected initial "Standard Test Method for Field Measurement of Infiltration Rate Using Double-Ring Infiltrometer with Sealed-Inner Ring", under the code number ASTM D5093-15 (2015), has four arcs leading to corresponding referenced scientific published papers $\left(\mathrm{PP}_{1,1} \& \mathrm{PP}_{1,2}\right)$ and ASTM standards $\left(\mathrm{ASTM}_{1,3}\right.$ \& $\left.\mathrm{ASTM}_{1,4}\right)$ as shown in Figures 1-3. The same procedure continues to the next generation and so forth until the seventh generation is formed. The integrated Ontology-Based Knowledge Network with all its ASTM standards and scientific published papers is presented in Figure A1 of the Appendix. However, a partial network that includes all the nodes of the first three generations is presented in Figure 1.

The dependence indices are considered as Boolean parameters, obtaining the values one or zero (meaning "referenced" or "not referenced", respectively) for sake of simplicity.

The interconnections between all nodes/concepts which represents soil/water physicochemical and biological properties and sub-processes of the integrated 
Table 1. Adjacency matrix for first generation relations, in accordance with part of the ontology-based knowledge network shown in Figure 2.

\begin{tabular}{cccccc}
\hline & ASTM D5093 & $\mathrm{PP}_{1,1}$ & $\mathrm{PP}_{1,2}$ & ASTM $_{1,3}$ & ASTM $_{1,4}$ \\
\hline ASTM D5093 & 0 & 1 & 1 & 1 & 1 \\
PP $_{1,1}$ & 0 & 0 & 0 & 0 & 0 \\
PP $_{1,2}$ & 0 & 0 & 0 & 0 & 0 \\
ASTM $_{1,3}$ & 0 & 0 & 0 & 0 & 0 \\
ASTM $_{1,4}$ & 0 & 0 & 0 & 0 & 0 \\
\hline
\end{tabular}

Table 2. Adjacency matrix for second generation relations, in accordance with part of the ontology-based knowledge network shown in Figure 2.

\begin{tabular}{ccccccccc}
\hline & $\mathrm{PP}_{1,1}$ & $\mathrm{PP}_{1,2}$ & $\mathrm{ASTM}_{1,3}$ & ASTM $_{1,4}$ & ASTM $_{2,1}$ & ASTM $_{2,2}$ & ASTM $_{2,3}$ & $\mathrm{PP}_{2,4}$ \\
\hline $\mathrm{PP}_{1,1}$ & 0 & 0 & 0 & 0 & 1 & 0 & 0 & 0 \\
$\mathrm{PP}_{1,2}$ & 0 & 0 & 0 & 0 & 0 & 1 & 0 & 0 \\
$\mathrm{ASTM}_{1,3}$ & 0 & 0 & 0 & 0 & 0 & 0 & 1 & 0 \\
$\mathrm{ASTM}_{1,4}$ & 0 & 0 & 0 & 0 & 0 & 0 & 0 & 1 \\
$\mathrm{ASTM}_{2,1}$ & 0 & 0 & 0 & 0 & 0 & 0 & 0 & 0 \\
$\mathrm{ASTM}_{2,2}$ & 0 & 0 & 0 & 0 & 0 & 0 & 0 & 0 \\
$\mathrm{ASTM}_{2,3}$ & 0 & 0 & 0 & 0 & 0 & 0 & 0 & 0 \\
$\mathrm{PP}_{2,4}$ & 0 & 0 & 0 & 0 & 0 & 0 & 0 & 0 \\
\hline
\end{tabular}

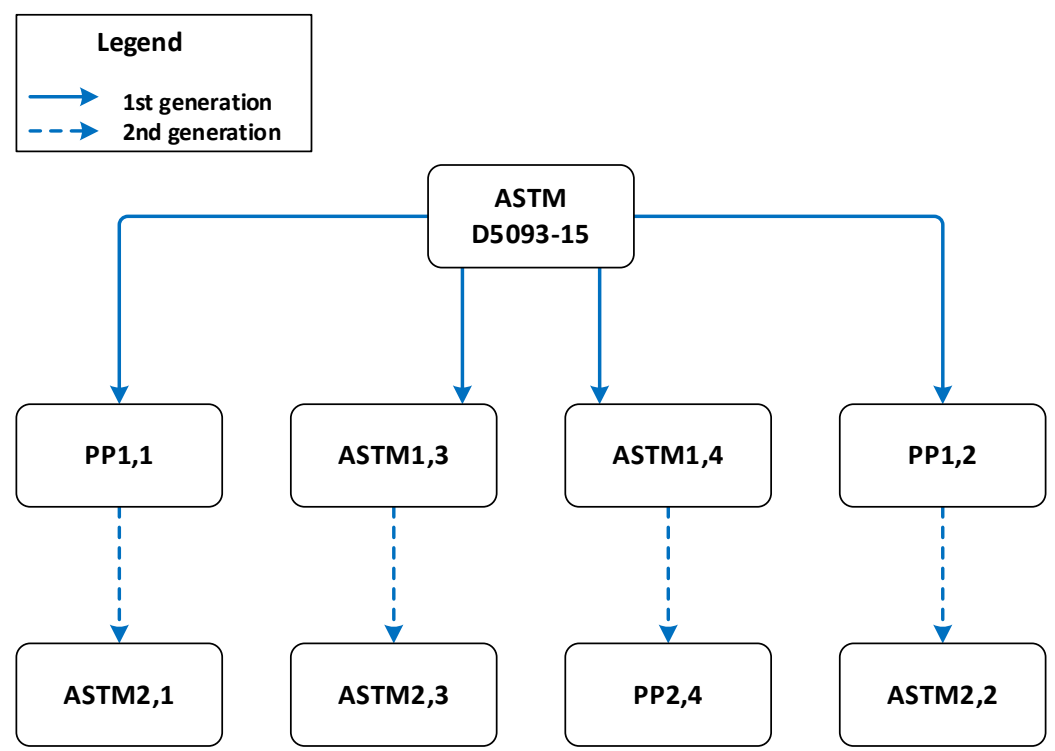

Figure 2. A tree representation of merely a part of the network of scientific published papers and ASTM standards for estimating the infiltration rate of contaminated water.

Ontology-Based Knowledge Network of Figure A2 of the Appendix, are presented and depicted with arcs. Each single arc consists of a starting point and a final point edge. In order to find and justify the correlations between all the 
nodes/concepts of Figure A1 \& Figure A2 of the Appendix, the selected concepts are corresponding to dependent and independent physical variables. According to the structure of the network, a dependent physical variable is the starting point of an arc that ends up (final pointed arc edge), to an independent variable. All these interconnections are documented according to the below three ways: 1) dependent and independent variables interconnected by using the logical operator "depends on" quoting existent explicit functions and equations, 2) dependent and independent variables interconnected by using the logical operator "depends on" quoting produced implicit functions, according to Rayleigh's method of indices, presented in Tables A1-A7 of the Appendix 3) dependent and independent variables interconnected by using the logical operator "related to" based on a logical dependence between the examined nodes-concepts-variables. All the above-described methods are detailed presented in the "contribution" column of Tables A1-A7 in the Appendix along with a Terminology Table in (SI units) of Table A8.

$\mathrm{PP}_{1,1}$ : Lassabatere et al. (2010), Effect of the settlement of sediments on water infiltration in two urban infiltration basins, Geoderma, 156(3-4), 316-325.

$\mathrm{PP}_{1,2}$ : Assouline (2013), Infiltration into soils: Conceptual approaches and solutions, Water resources research, 49(4), 1755-1772.

ASTM $_{1,3}$ : ASTM C1585-20 (2020), Standard Test Method for Measurement of Rate of Absorption of Water by Hydraulic-Cement Concretes.

ASTM $_{1,4}$ : ASTM D3385-18 (2018), Standard Test Method for Infiltration Rate of Soils in Field Using Double-Ring Infiltrometer.

ASTM $_{2,1}$ : ASTM D3385-18 (2018), Standard Test Method for Infiltration Rate of Soils in Field Using Double-Ring Infiltrometer.

ASTM $_{2,2}$ : ASTM D5126-16e1 (2016), Standard Guide for Comparison of Field Methods for Determining Hydraulic Conductivity in Vadose Zone.

ASTM $_{2,3}$ : ASTM C1792-14 (2014), Standard Test Method for Measurement of Mass Loss versus Time for One-Dimensional Drying of Saturated Concretes $\mathrm{PP}_{2,4}$ : Di Prima et al. (2016), Testing a new automated single ring infiltrometer for Beerkan infiltration experiments, Geoderma, 262, 20-34.

\section{Discussion}

The network presented on Figure A1 of the Appendix is structured by using all relevant ASTM standardization available to build up rigid constructed generations. Nonetheless, no other international fully approved standardized methodology was adopted (e.g. ISO, DIN, BS, EN etc.). A terminology Table is an integral part of the Ontology-Based Knowledge Network and is a very useful medium to avoid scientists of boundary disciplines misapprehension/misleading to even basic concepts.

The following presented paradigm could be a characteristic one to hydraulic engineers and earth scientists that their activities are located in between interdisciplinary knowledge areas. The term "infiltration" forms a continuum with 
"percolation" and "seepage" terms, so that several authors use them interchangeably, as quasi synonyms. From a topological point of view infiltration is considered to be the water movement into the soil while percolation refers to the water path within/through the soil until it reaches the water table. Consequently, it seems that there is a first interface between the infiltration and percolation zones as well as another subsequent interface between percolation zone and water table. On the other hand, seepage is the slow escape/leakage of water on or near the earth surface simulating a downhill route possible formed by natural phenomena or local constitution of earth, implying difference in permeability enhanced by the presence of clay-loam soils and certain minerals.

\section{Conclusion}

The presented multi-generation ontological network, which employs standardization of techniques/methods relevant to sedimentation during and after infiltration, is merely the beginning of a forthcoming profound interdisciplinary expansion. The corresponding network of standards and recommended practices might receive further enrichment, incorporated e.g. ISO/EN standards and more profound phenomenological knowledge related to porous media infiltration. This could be achieved by presented new interconnections among conceptual levels and deeper generation formation analysis upon the already proposed structure.

\section{Conflicts of Interest}

The authors declare no conflicts of interest regarding the publication of this paper.

\section{References}

Assouline, S. (2013). Infiltration into Soils: Conceptual Approaches and Solutions. Water Resources Research, 49, 1755-1772. https://doi.org/10.1002/wrcr.20155

ASTM C1585-20 (2020). Standard Test Method for Measurement of Rate of Absorption of Water by Hydraulic-Cement Concretes. West Conshohocken, PA: ASTM International.

ASTM C1792-14 (2014). Standard Test Method for Measurement of Mass Loss versus Time for One-Dimensional Drying of Saturated Concretes. West Conshohocken, PA: ASTM International.

ASTM D3385-18 (2018). Standard Test Method for Infiltration Rate of Soils in Field Using Double-Ring Infiltrometer. West Conshohocken, PA: ASTM International.

ASTM D5093-15 (2015). Standard Test Method for Field Measurement of Infiltration Rate Using Double-Ring Infiltrometer with Sealed-Inner Ring. West Conshohocken, PA: ASTM International.

ASTM D5126-16e1 (2016). Standard Guide for Comparison of Field Methods for Determining Hydraulic Conductivity in Vadose Zone. West Conshohocken, PA: ASTM International.

Borst, W. N. (1997). Construction of Engineering Ontologies for Knowledge Sharing and Reuse. Enschede: Centre for Telematics and Information Technology (CTIT).

https://www.semanticscholar.org/paper/Construction-of-Engineering-Ontologies-for-S haring-Borst/205e142ca3eb360be04988c80cbe3819523868f1 
Di Prima, S. et al. (2016). Testing a New Automated Single Ring Infiltrometer for Beerkan Infiltration Experiments. Geoderma, 262, 20-34.

https://doi.org/10.1016/j.geoderma.2015.08.006

Du, H. et al. (2016). An Ontology of Soil Properties and Processes. 15th International Semantic Web Conference, Kobe, 17-21 October 2016, 30-37. https://doi.org/10.1007/978-3-319-46547-0_4

Genesereth, M. R., \& Nilsson, N. J. (1987). Logical Foundations of Artificial Intelligence. Los Altos, CA: Morgan Kaufmann.

Gruber, T. R. (1995). Toward Principles for the Design of Ontologies Used for Knowledge Sharing. International Journal Human-Computer Studies, 43, 907-928. https://doi.org/10.1006/ijhc.1995.1081

Guarino, N. (1995). Ontologies and Knowledge Bases: Towards a Terminological Clarification. In Towards Very Large Knowledge Bases (pp. 25-32). Amsterdam: IOS Press. https://www.researchgate.net/publication/220041941_Ontologies_and_knowledge_bas es_towards_a_terminological_clarification

Heeptaisong, T., \& Srivihok, A. (2010). Ontology Development for Searching Soil Knowledge. The 9th International Conference on e-Business (iNCEB2010), Bangkok, 18-19 November 2010, 102-107.

https://citeseerx.ist.psu.edu/viewdoc/download?doi=10.1.1.463.2552\&rep=rep1\&type= pdf

Lassabatere, L. et al. (2010). Effect of the Settlement of Sediments on Water Infiltration in Two Urban Infiltration Basins. Geoderma, 156, 316-325.

https://doi.org/10.1016/j.geoderma.2010.02.031

Mikkelsen, P. S. et al. (1997). Pollution of Soil and Groundwater from Infiltration of Highly Contaminated Stormwater-A Case Study. Water Science and Technology, 36, 325-330. https://doi.org/10.2166/wst.1997.0687

Patle, G. T. et al. (2018). Estimation of Infiltration Rate from Soil Properties Using Regression Model for Cultivated Land. Geology, Ecology \& Landscapes, 3, 1-13. https://doi.org/10.1080/24749508.2018.1481633

Roche, C. (2003). Ontology: A Survey. IFAC Symposium Proceedings, 36, 187-192. https://doi.org/10.1016/S1474-6670(17)37715-7

Studer, R. et al. (1998). Knowledge Engineering: Principles and Methods. Data \& Knowledge Engineering, 25, 161-198. https://doi.org/10.1016/S0169-023X(97)00056-6

Tejedor, M. et al. (2013). Soil Properties Controlling Infiltration in Volcanic Soils (Tenerife, Spain). Soil Science Society of America Journal, 77, 202-212. https://doi.org/10.2136/sssaj2012.0132

Uschold, M., \& Grüninger, M. (1996). Ontologies: Principles, Methods and Applications. The Knowledge Engineering Review, 11, 93-136. https://doi.org/10.1017/S0269888900007797

Wang, P. et al. (2017). Effects of Urbanization, Soil Property and Vegetation Configuration on Soil Infiltration of Urban Forest in Changchun, Northeast China. Chinese Geographical Science, 28, 482-494. https://doi.org/10.1007/s11769-018-0953-7

Weng, S. S., \& Chang, H. L. (2008). Using Ontology Network Analysis for Research Document Recommendation. Expert Systems with Applications, 34, 1857-1869. https://doi.org/10.1016/j.eswa.2007.02.023

Wood, J. C. et al. (1987). Important Factors Influencing Water Infiltration and Sediment Production on Arid Lands in New Mexico. Journal of Arid Environments, 12, 111-118. https://doi.org/10.1016/S0140-1963(18)31181-9 


\section{Appendix}

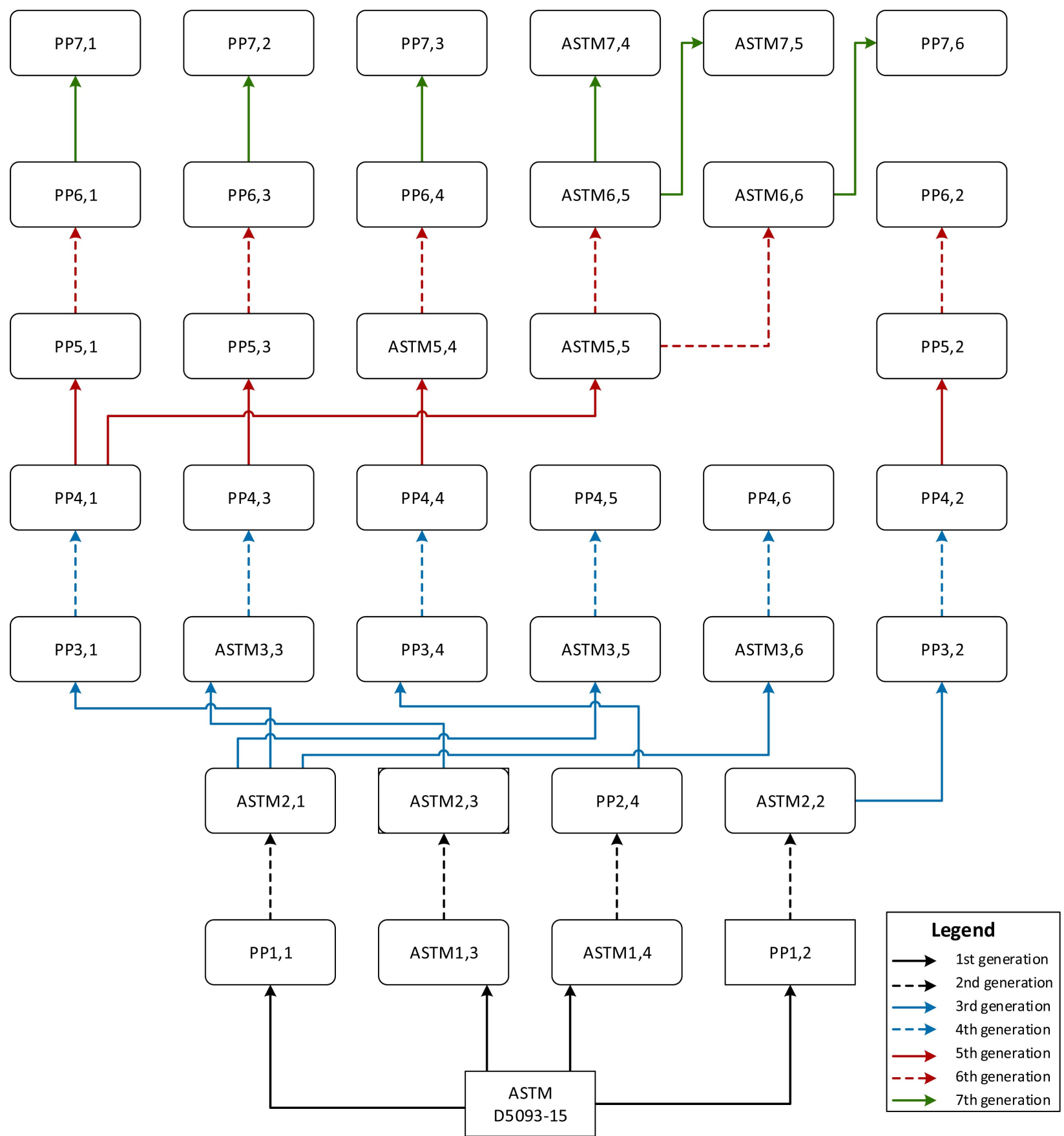

Figure A1. The integrated ontology-based knowledge network that represents the interconnections between ASTM standards $\left(\mathrm{ASTM}_{i, n}\right)$ and scientific published papers $\left(\mathrm{PP}_{i, n}\right)$ formed in accordance with the third column named "node" of each Tables A1-A7 of the Appendix. 


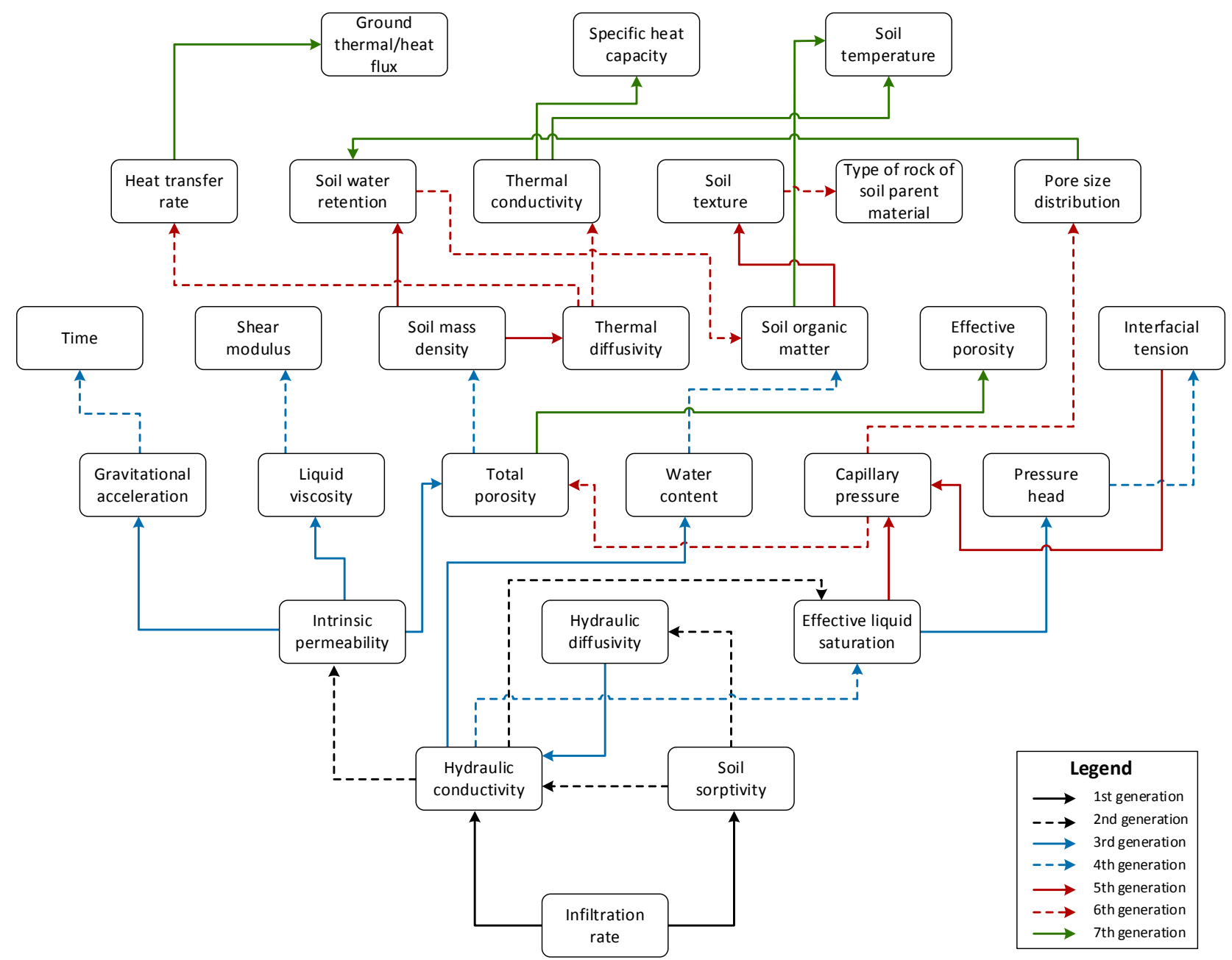

Figure A2. The integrated ontology-based knowledge network that represents the interconnections between soil/water concepts/properties formed in accordance with the fifth column named "concept" of each Tables A1-A7 of the Appendix. 
Table A1. Description of all nodes (see Figure A1) under the form of Standards or published papers and the corresponding concepts (see Figure A2) which are included in the first generation.

\begin{tabular}{|c|c|c|c|c|c|c|}
\hline Row & Column & Node & $\begin{array}{l}\text { Appendix } \\
\text { references }\end{array}$ & Concept & $\begin{array}{l}\text { Depends } \\
\text { on/related to }\end{array}$ & Contribution \\
\hline \multicolumn{7}{|c|}{0 Generation } \\
\hline 0 & 1 & $\begin{array}{c}\text { ASTM } \\
\text { D5093-15 }\end{array}$ & [7] & $\begin{array}{l}\text { Infiltration } \\
\text { rate }\end{array}$ & 0 & 1 \\
\hline \multicolumn{7}{|c|}{$1^{\text {st }}$ Generation } \\
\hline Row & Column & Node & $\begin{array}{l}\text { Appendix } \\
\text { references }\end{array}$ & Concept & $\begin{array}{c}\text { Depends } \\
\text { on/related to }\end{array}$ & Contribution \\
\hline
\end{tabular}

The infiltration rate $q(t)$ depends on saturated hydraulic conductivity $\left(K_{s}\right)$ according to the equation [28], 5c, page 318 :

$1 \quad 1 \quad \mathrm{PP}_{1,1}$

[28]

$1 \quad 2 \quad \mathrm{PP}_{1,2}$

[15]

$13 \quad \mathrm{ASTM}_{1,3}$

[2]

Soil

Sorptivity

Sorptivity

ASTM D5093-15

introduced by Brutsaert, 1977, where the terms, definitions and dimensions of $\left(q(t), K_{s}, S, t, \beta_{\circ}\right)$ are presented in detail in terminology (Table A8) of the Appendix. For clarification purposes, $(S)$ refers to the sorptivity.

The infiltration rate $q(t)$ depends on soil sorptivity $(S)$, according to the implicit function:

$$
q(t)=\left(\frac{z}{t}\right) * f\left((S h),\left(\frac{t^{2} * \gamma}{\rho_{w} * z^{3}}\right),\left(\frac{\gamma}{\psi * z}\right),(R i),\left(\frac{t * \gamma}{\mu * z}\right),\left(\frac{z}{v_{z} * t}\right),\right.
$$$$
\text { ASTM }
$$$$
\text { D5093-15 }
$$

where the terms, definitions and dimensions of

( $\left.q(t), z, t, S h, \gamma, \rho_{w}, \psi, R i, \mu, v_{z}, \rho_{s}, k_{\text {inr }}, S c, H, S\right)$ are presented in detail in the terminology (Table A8) of the Appendix. Rayleigh's method of indices was deployed along with the echelon matrix procedure as an additional confirmation method.

The infiltration rate $q(t)$ depends on hydraulic conductivity $(K)$ according to the implicit function:

$$
\begin{aligned}
q(t)=\left(\frac{H}{t}\right) * f & \left((S h),(S c),\left(\frac{\mu}{\psi * t}\right),\left(\frac{H}{g * t^{2}}\right),\left(\frac{H}{v_{z} * t}\right),\left(\frac{H^{2}}{A}\right),(R e),\right. \\
& \left.\left(\frac{\mu * t}{\rho_{s} * H^{2}}\right),\left(\frac{H^{2}}{k_{\text {intr }}}\right),\left(\frac{H^{2}}{t^{*} D}\right),(R i),\left(\frac{\mu * H}{t * \gamma}\right), \Phi, \theta, S_{e}, n, i\right)
\end{aligned}
$$

Hydraulic ASTM conductivity D5093-15 where the terms, definitions and dimensions of

$\left(q(t), H, t, S h, S c, \mu, \psi, g, v_{z}, A, R e, \rho_{s}, k_{\text {int }}, D, R i, \gamma, \Phi, \theta, S_{e}, n, i\right)$ are presented in detail in the terminology (Table A8) of the Appendix. $(A)$ refers to cross section of the infiltrometer cylinder, $(\Phi)$ is the total porosity, $(\theta)$ is the liquid content/soil-water content, $(n)$ is the pore size distribution index. Rayleigh's method of indices was deployed along with the echelon matrix procedure as an additional confirmation method. 
Table A2. Description of all nodes (see Figure A1) under the form of standards or published papers and the corresponding concepts (see Figure A2) which are included in the second generation.

\begin{tabular}{llll}
\hline $2^{\text {nd }}$ Generation & & \\
\hline Row Column Node & $\begin{array}{c}\text { Appendix } \\
\text { references }\end{array}$ Concept $\begin{array}{c}\text { Depends on/ } \\
\text { Related to }\end{array}$ & Contribution \\
\hline
\end{tabular}

Hydraulic conductivity $(K)$ depends on intrinsic permeability $\left(k_{\text {intr }}\right)$, according to the implicit function:

$2 \quad 1 \quad \mathrm{ASTM}_{2,1} \quad$ [5] Intrinsic

[5] Permeability

$2 \quad 2 \quad$ ASTM $_{2,2}$

[8]

Hydraulic conductivity

Hydraulic Diffusivity

$\operatorname{ASTM}_{1,3}$

$$
\begin{gathered}
K=\left(v_{z}\right) * f\left(\left(\frac{v_{z}}{q}\right),\left(\frac{\rho * v_{z}^{2}}{\psi}\right),\left(\frac{1}{R i}\right),\left(\frac{1}{R e}\right),\left(\frac{H^{2}}{A_{\text {inf }}}\right),\left(\frac{\rho}{\rho_{s}}\right),\left(\frac{H^{2}}{k_{\text {inr }}}\right),\right. \\
\left.\left(\frac{H}{v_{z} * t}\right),\left(\frac{v_{z} * H}{D}\right),\left(\frac{\rho * v_{z}^{2} * H}{\sigma}\right), \Phi, \theta, S_{e}, n, i\right)
\end{gathered}
$$

$\mathrm{PP}_{1,1} \quad$ The terms, definitions and dimensions of

$\left(K, v_{z}, q, \rho, \psi, R i, R e, H, A_{i n f}, \rho_{s}, k_{i n r}, t, D, \sigma, \Phi, \theta, S_{e}, n, i\right)$ are presented in detail in the below terminology (Table A8) of the Appendix. For clarification purposes, $(q)$ refers to infiltration rate, $(\Phi)$ is the total porosity, $(\theta)$ is the liquid content/soil-water content, $(n)$ is pore size distribution index. Rayleigh's method of indices was deployed along with the echelon matrix procedure as an additional confirmation method.

Soil sorptivity $(S)$ depends on hydraulic conductivity $(K)$, according to the implicit function:

$$
\begin{gathered}
S=\left(\frac{z}{t^{0.5}}\right) * f\left(\left(\frac{z}{q * t}\right),(S h),(R e),\left(\frac{\gamma}{\psi * z}\right),(R i),\left(\frac{t * \gamma}{\mu * z}\right),\left(\frac{z}{v_{z} * t}\right),\right. \\
\left.\left(\frac{t^{2} * \gamma}{\rho_{s} * z^{3}}\right),\left(\frac{z^{2}}{k_{\text {intr }}}\right),(S c),\left(\frac{z}{H}\right),\left(\frac{z}{h_{c}}\right), \Phi, \theta, n\right)
\end{gathered}
$$

$\mathrm{PP}_{1,2}$

Where the terms, definitions and dimensions of

$\left(S, z, t, q, S h, R e, \gamma, \psi, R i, \mu, v_{z}, \rho_{s}, k_{\text {intr }}, S c, H, h_{c}, \Phi, \theta, n\right)$ are presented in detail in the below terminology (Table A8) of the Appendix. For clarification purposes, $(q)$ refers to infiltration rate, $(\Phi)$ is the total porosity, $(\theta)$ is the liquid content/soil-water content, $(n)$ is pore size distribution index. Rayleigh's method of indices was deployed along with the echelon matrix procedure as an additional confirmation method.

Soil sorptivity $(S)$ depends on hydraulic diffusivity $(D)$, according to the implicit function:

$S=\left(\frac{z}{t^{0.5}}\right) * f\left((S h),\left(\frac{M}{\rho * z^{3}}\right),\left(\frac{M}{\psi * t^{2} * z}\right),\left(\frac{z}{g * t^{2}}\right),\left(\frac{\mu * t * z}{M}\right)\right.$,

$23 \quad$ ASTM $_{2,3}$

$[3]$

$$
\left.\left(\frac{M}{\rho_{s} * z^{3}}\right),\left(\frac{z^{2}}{k_{\text {inr }}}\right),(S c),\left(\frac{M}{t^{2} * \gamma}\right)\right)
$$

Where the terms, definitions and dimensions of $\left(S, z, t, S h, M, \rho, \psi, g, \mu, \rho_{s}, k_{\text {intr }}, S c, \gamma\right)$ are presented in detail in the terminology (Table A8) of the Appendix. For clarification purposes, $(M)$ refers to the initial liquid mass. Rayleigh's method of indices was deployed along with the echelon matrix procedure as an additional confirmation method. Hydraulic conductivity $(K)$ depends on effective saturation or degree of saturation $\left(S_{e}\right)$, according to Van Genuchten-Mualem model [20], (equation 15 c, page 23) initially introduced by van Genuchten, 1980 and Mualem, 1976:

Effective liquid saturation
$\operatorname{ASTM}_{1,4}$ where the terms, definitions and dimensions of $\left(K(\theta), K_{s}, S_{e}, m\right)$ are presented in detail in the terminology (Table A8) of the Appendix (where $\left.m=1-\frac{1}{n}\right)$. 
Table A3. Description of all nodes (see Figure A1) under the form of Standards or published papers and the corresponding concepts (see Figure A2) which are included in the third generation.

\begin{tabular}{lll}
\hline $3^{\text {rd }}$ Generation & & \\
\hline Row Column Node $\begin{array}{c}\text { Appendix } \\
\text { references }\end{array}$ & Concept $\begin{array}{c}\text { Depends on/ } \\
\text { Related to }\end{array}$ & Contribution
\end{tabular}

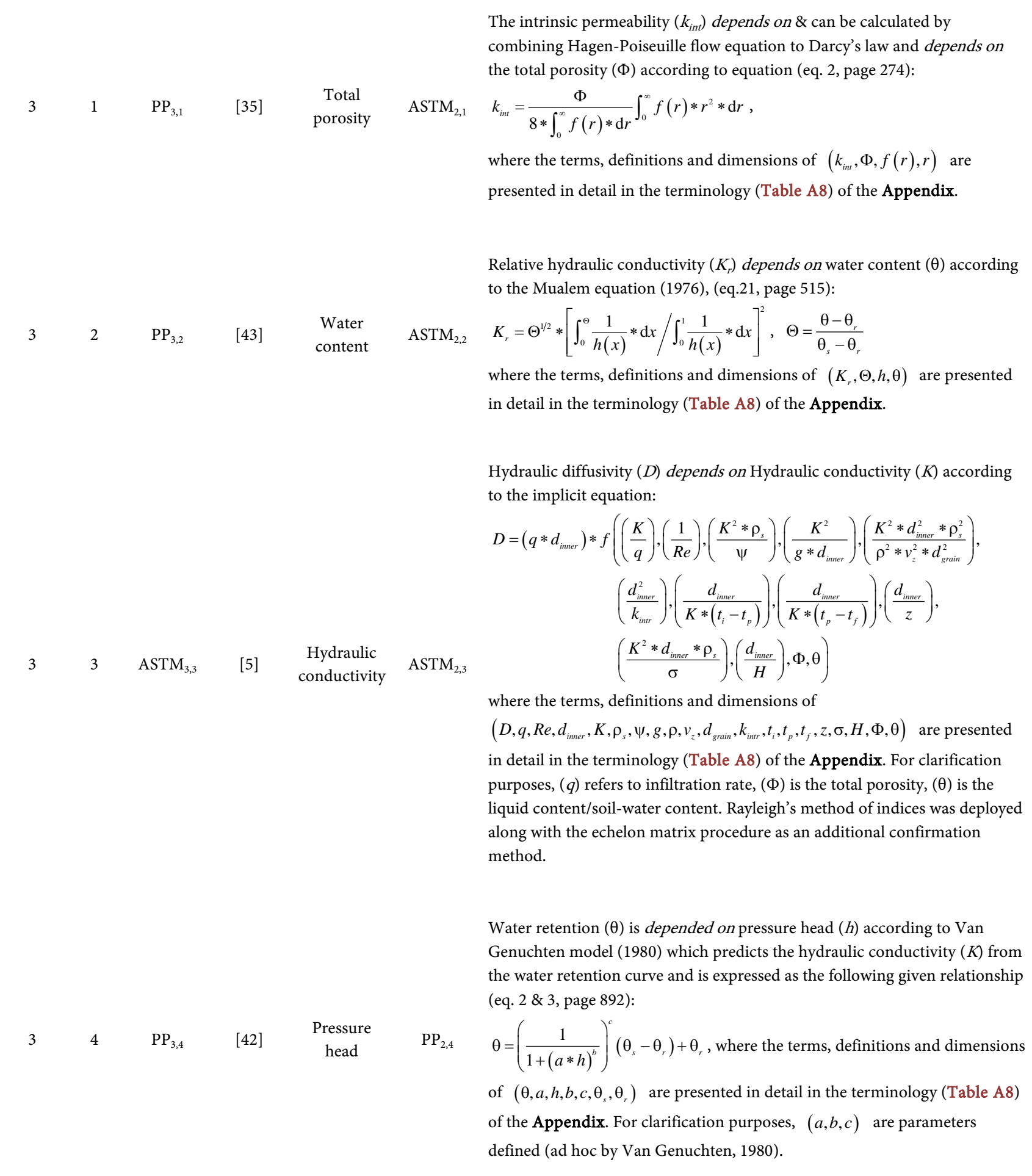




\section{Continued}

$5 \quad \operatorname{ASTM}_{3,5}$

$[11]$

Liquid viscosity

$\mathrm{ASTM}_{2,1}$

Where the terms, definitions and dimensions of $\left(k_{\text {inr }}, h_{c}, q, t, S h, v_{2}, S c, \rho_{s}, \psi, \mu, R i, D, R e, z, C a, C_{i}, T_{i}, T, \Phi, \theta, S_{e}, n, i, K_{s}, \frac{\mathrm{d} C_{i}}{\mathrm{~d} t}\right)$ are presented in detail in the terminology (Table A8) of the Appendix. ( $q$ ) refers to infiltration rate, $(\Phi)$ is the total porosity, $(\theta)$ is the liquid content/soil-water content, $(n)$ is pore size distribution index, $\left(K_{s}\right)$ is fluid solubility. Rayleigh's method of indices was deployed along with the echelon matrix procedure as an additional confirmation method.

Intrinsic permeability $\left(k_{\text {intr }}\right)$ depends on gravitational acceleration $(g)$, according to the implicit equation:

$k_{\text {intr }}=h_{c}^{2} * f\left(\left(\frac{h_{c}}{q * t}\right),(S h),\left(\frac{h_{c}}{v_{z} * t}\right),(S c),\left(\frac{\rho_{s} * h_{c}^{2}}{\psi * t^{2}}\right),\left(\frac{\rho_{s} * h_{c}^{2}}{\mu * t}\right),(R i),\left(\frac{h_{c}^{2}}{t * D}\right)\right.$, Gravitational ASTM $_{2,1}$ $\left.(R e),\left(\frac{h_{c}}{z}\right),(C a),\left(\frac{C_{i}}{t *\left(\frac{\mathrm{d} C_{i}}{\mathrm{~d} t}\right)}\right),\left(\frac{T_{i}}{h_{c} *\left(\frac{\mathrm{d} T}{\mathrm{~d} z}\right)}\right), \Phi, \theta, S_{e}, n, i, K_{s}\right)$

Where the terms, definitions and dimensions of $\left(k_{\text {intr }}, d_{\text {grain }}, q, t, S h, R e, S c, \mu, \psi, \rho_{s}, d_{\text {ring }}, R i, D, \sigma, h_{c}\right)$ are presented in detail in the terminology (Table A8) of the Appendix. For clarification purposes, $(q)$ refers to infiltration rate. Rayleigh's method of indices was deployed along with the echelon matrix procedure as an additional confirmation method. 
Table A4. Description of all nodes (see Figure A1) under the form of Standards or published papers and the corresponding concepts (see Figure A2) which are included in the fourth generation.

\begin{tabular}{|c|c|c|c|c|c|c|}
\hline \multicolumn{7}{|c|}{$4^{\text {th }}$ Generation } \\
\hline Row & Column & Node & $\begin{array}{l}\text { Appendix } \\
\text { references }\end{array}$ & Concept & $\begin{array}{c}\text { Depends on/ } \\
\text { Related to }\end{array}$ & Contribution \\
\hline 4 & 1 & $\mathrm{PP}_{4,1}$ & {$[33]$} & $\begin{array}{c}\text { Soil } \\
\text { mass density }\end{array}$ & $\mathrm{PP}_{3,1}$ & $\begin{array}{l}\text { According to Nimmo (2004) equation } \alpha=\left(1-\frac{\rho_{s}}{\rho_{p}}\right) \text { (equation 1, page 3), } \\
\text { total porosity }(\alpha) \text { or }(\Phi) \text { depends on soil bulk density }\left(\rho_{s}\right) \text { and soil mass } \\
\text { density or particle density }\left(\rho_{p}\right) \text {, where the terms, definitions and dimensions } \\
\text { of }\left(\alpha, \rho_{s}, \rho_{p}\right) \text { are presented in detail in the terminology (Table A8) of the } \\
\text { Appendix. }\end{array}$ \\
\hline 4 & 2 & $\mathrm{PP}_{4,2}$ & {$[21]$} & $\begin{array}{l}\text { Soil } \\
\text { organic } \\
\text { matter }\end{array}$ & $\mathrm{PP}_{3,2}$ & $\begin{array}{l}\text { Water content is related to Soil Organic Matter (SOM). Soil organic matter } \\
\text { content and composition effects on water content and soil water potential } \\
\text { (pages 2282, 2285) }\end{array}$ \\
\hline 4 & 3 & $\mathrm{PP}_{4,3}$ & {$[32]$} & $\begin{array}{l}\text { Effective } \\
\text { liquid } \\
\text { saturation }\end{array}$ & $\operatorname{ASTM}_{3,3}$ & $\begin{array}{l}\text { Hydraulic conductivity }(K) \text { depends on Effective liquid saturation }\left(S_{e}\right) \\
\text { according to Kozeny's approach and Corey's effective saturation definition } \\
\text { (Mualem 1976), (equation } 1 \& 2 \text {, page 513): } \\
K(\theta)=K_{s} *\left(S_{e}\right)^{n}, S_{e}=\frac{\theta-\theta_{r}}{\theta_{s}-\theta_{r}} \\
\text { Where the terms, definitions and dimensions of }\left(K(\theta), K_{s}, S_{e}, \theta, \theta_{r}, \theta_{s}, n\right) \\
\text { are presented in detail in the terminology (Table A8) of the Appendix. } \\
\text { Where }(\theta) \text { is the liquid content/soil-water content and }(n) \text { is a shape } \\
\text { parameter. }\end{array}$ \\
\hline 4 & 4 & $\mathrm{PP}_{4,4}$ & [19] & $\begin{array}{l}\text { Interfacial } \\
\text { tension }\end{array}$ & $\mathrm{PP}_{3,4}$ & $\begin{array}{l}\text { Pressure head }(h) \text {, depends on interfacial tension }(\sigma) \text { according to } \\
\text { Young-Laplace equation, (equation 3, page 1011): } \\
h=-\frac{2 * \sigma * \cos \varphi}{\rho * r * g} \\
\text { Where the terms, definitions and dimensions of }(h, \sigma, \varphi, \rho, r, g) \text { are } \\
\text { presented in detail in the terminology (Table A8) of the Appendix. }(\varphi) \text { is the } \\
\text { average contact angle of the liquid-air interface and }(r) \text { is the average pore } \\
\text { space. }\end{array}$ \\
\hline 4 & 5 & $\mathrm{PP}_{4,5}$ & [38] & $\begin{array}{l}\text { Shear } \\
\text { modulus/ } \\
\text { Modulus of } \\
\text { rigidity }\end{array}$ & $\operatorname{ASTM}_{3,5}$ & $\begin{array}{l}\text { The viscosity }(\eta) \text { of the fluid depends on } \& \text { can be varied by the variation of } \\
\text { the angular relaxation frequency }\left(\omega_{1}\right) \text { and the shear modulus }\left(c_{44}\right) \text {, according } \\
\text { to the equation: } \eta=\frac{c_{44}}{\omega_{1}} \text {, (equation } 9 \text {, page } 239 \text { ), where the terms, } \\
\text { definitions and dimensions of }\left(\eta, c_{44}, \omega_{1}\right) \text { are presented in detail in the } \\
\text { below terminology (Table A8) of the Appendix. }\end{array}$ \\
\hline 4 & 6 & $\mathrm{PP}_{4,6}$ & {$[22]$} & Time & $\operatorname{ASTM}_{3,6}$ & The gravitational acceleration $(g)$ related to time. \\
\hline
\end{tabular}

${ }^{1}$ No model/function or quantitative path exists, interconnecting the concepts, though experimentally proven. 
Table A5. Description of all nodes (see Figure A1) under the form of Standards or published papers and the corresponding concepts (see Figure A2) which are included in the fifth generation.

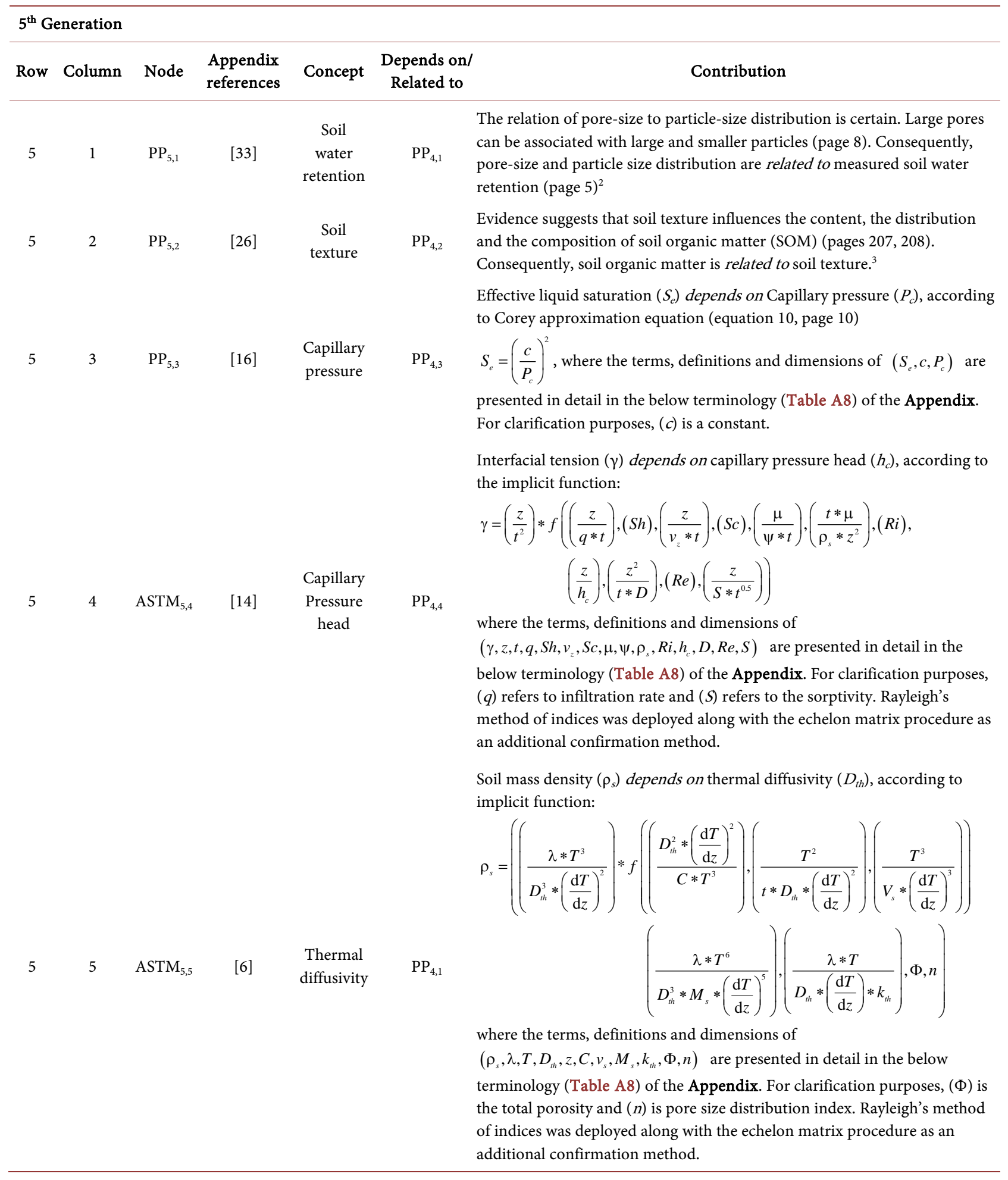

${ }^{2}$ No model/function or quantitative path exists, interconnecting the concepts.

${ }^{3} \mathrm{No}$ model/function or quantitative path exists, interconnecting the concepts. 
Table A6. Description of all nodes (see Figure A1) under the form of Standards or published papers and the corresponding concepts (see Figure A2) which are included in the sixth generation.

\begin{tabular}{lll}
\hline $6^{\text {th }}$ Generation & & \\
\hline Row Column Node $\begin{array}{c}\text { Appendix } \\
\text { references }\end{array}$ & Concept $\begin{array}{c}\text { Depends on/ } \\
\text { Related to }\end{array}$ & Contribution
\end{tabular}

\begin{tabular}{|c|c|c|c|c|c|c|}
\hline 6 & 1 & $\mathrm{PP}_{6,1}$ & [47] & $\begin{array}{l}\text { Soil } \\
\text { organic } \\
\text { matter }\end{array}$ & $\mathrm{PP}_{5,1}$ & $\begin{array}{l}\text { Results show that soil water retention is related to soil organic matter (SOM) } \\
\text { (page 3086). Soil organic matter affects soil water retention because of its } \\
\text { affinity to water and its influence on soil structure and bulk density (page } \\
3087)^{4}\end{array}$ \\
\hline 6 & 2 & $\mathrm{PP}_{6,2}$ & [18] & $\begin{array}{l}\text { Type } \\
\text { of rock of } \\
\text { soil parent } \\
\text { material }\end{array}$ & $\mathrm{PP}_{5,2}$ & $\begin{array}{l}\text { The soil texture heterogeneity is controlled by the type of rock that } \\
\text { constitutes the soil parent material (pages } 157,163 \text { ). Consequently, soil } \\
\text { texture is related to type of rock of soil parent material }{ }^{5}\end{array}$ \\
\hline 6 & 3 & $\mathrm{PP}_{6,3}$ & [39] & $\begin{array}{c}\text { Total } \\
\text { Porosity }\end{array}$ & $\mathrm{PP}_{5,3}$ & $\begin{array}{l}\text { The capillary pressure }\left(P_{c}\right) \text { depends on the porosity }(\Phi) \text {, (equation 3.4.1.14, } \\
\text { page 58). } \\
P_{c}=\left(\frac{\Phi}{K}\right)^{0,5} * \sigma * J(s) \text {, where the terms, definitions and dimensions of } \\
\left(P_{c}, \Phi, K, \sigma, J(s), s\right) \text { are presented in detail in the below terminology } \\
\text { (Table A8) of the Appendix. }\end{array}$ \\
\hline 6 & 4 & $\mathrm{PP}_{6,4}$ & [30] & $\begin{array}{c}\text { Pore size } \\
\text { distribution }\end{array}$ & ASTM $_{5,4}$ & $\begin{array}{l}\text { In van Genuchten's model, the capillary pressure }\left(P_{c}\right) \text { is depended on the } \\
\text { pore size distribution }(n) \text {, (eq. 2, page 3619): } \\
P_{c}=\mathrm{a}^{-1} *\left(S_{e}^{\left(-\frac{1}{m}\right)}-1\right)^{\frac{1}{n}} \text {, where the terms, definitions and dimensions of } \\
\left(P_{c}, \mathrm{a}, S_{e}, m, n\right) \text { are presented in detail in the below terminology (Table A8) } \\
\text { of the Appendix. }\end{array}$ \\
\hline 6 & 5 & $\operatorname{ASTM}_{6,5}$ & [1] & $\begin{array}{c}\text { Thermal } \\
\text { conductivity }\end{array}$ & $\mathrm{ASTM}_{5,5}$ & $\begin{array}{l}\text { Thermal diffusivity }\left(D_{t h}\right) \text { depends on thermal conductivity }(\lambda) \text {, according to } \\
\text { the implicit function: } \\
D_{t h}=\left(\frac{V_{s}^{\frac{2}{3}}}{t}\right) f\left(\left(\frac{V_{s}^{\frac{1}{3}} * M_{s}}{\lambda * t^{3} * T}\right),\left(\frac{V_{s}^{\frac{2}{3}}}{C * t^{2} * T}\right),\left(\frac{M_{s}}{\rho_{s} * V_{s}}\right) \text {, }\right. \\
\qquad\left(\frac{T}{\left.\left.V_{s}^{\frac{1}{3}} *\left(\frac{\mathrm{d} T}{\mathrm{~d} z}\right)\right),\left(\frac{M_{s}}{t^{2} * T * k_{t h}}\right), \Phi, n\right)}\right) \\
\text { where the terms, definitions and dimensions of } \\
\left(D_{t h}, V_{s}, t, M_{s}, \lambda, T, C, \rho_{s}, z, k_{t h}, \Phi, n\right) \text { are presented in detail in the below } \\
\text { terminology (Table A8) of the Appendix. For clarification purposes, }(\Phi) \text { is } \\
\text { the total porosity and }(n) \text { is pore size distribution index. Rayleigh's method } \\
\text { of indices was deployed along with the echelon matrix procedure as an } \\
\text { additional confirmation method. }\end{array}$ \\
\hline
\end{tabular}

${ }^{4} \mathrm{No}$ model/function or quantitative path exists, interconnecting the concepts.

${ }^{5}$ No model/function or quantitative path exists, interconnecting the concepts. 


\section{Continued}

Thermal diffusivity $\left(D_{t h}\right)$ depends on heat transfer rate $\left(q_{H}\right)$, according to the implicit function:

$$
\begin{aligned}
D_{t h}=\alpha_{s}=\left(\frac{z^{2}}{t}\right) * f & \left(\left(\frac{\rho_{s} * z^{4}}{\lambda_{s} * T_{i} * t^{3}}\right),\left(\frac{z^{2}}{C_{s} * t^{2} * T_{i}}\right),\left(\frac{z^{3}}{V_{s}}\right),\right. \\
& \left.\left(\frac{T_{i}}{\left(\frac{\mathrm{d} T}{\mathrm{~d} z}\right) * z}\right),(B i),\left(\frac{z^{2}}{A}\right),\left(\frac{\rho_{s} * z^{5}}{t^{2} * q_{H}}\right)\right)
\end{aligned}
$$

Where the terms, definitions and dimensions of $\left(D_{t h}, z, t, \rho_{s}, \lambda_{s}, T_{i}, C_{s}, V_{s}, B i, A, q_{H}\right)$ are presented in detail in the below terminology (Table A8) of the Appendix. For clarification purposes, $(A)$ refers to specimen sectional area. Rayleigh's method of indices was deployed along with the echelon matrix procedure as an additional confirmation method. 
Table A7. Description of all nodes (see Figure A1) under the form of Standards or published papers and the corresponding concepts (see Figure A2) which are included in the seventh generation.

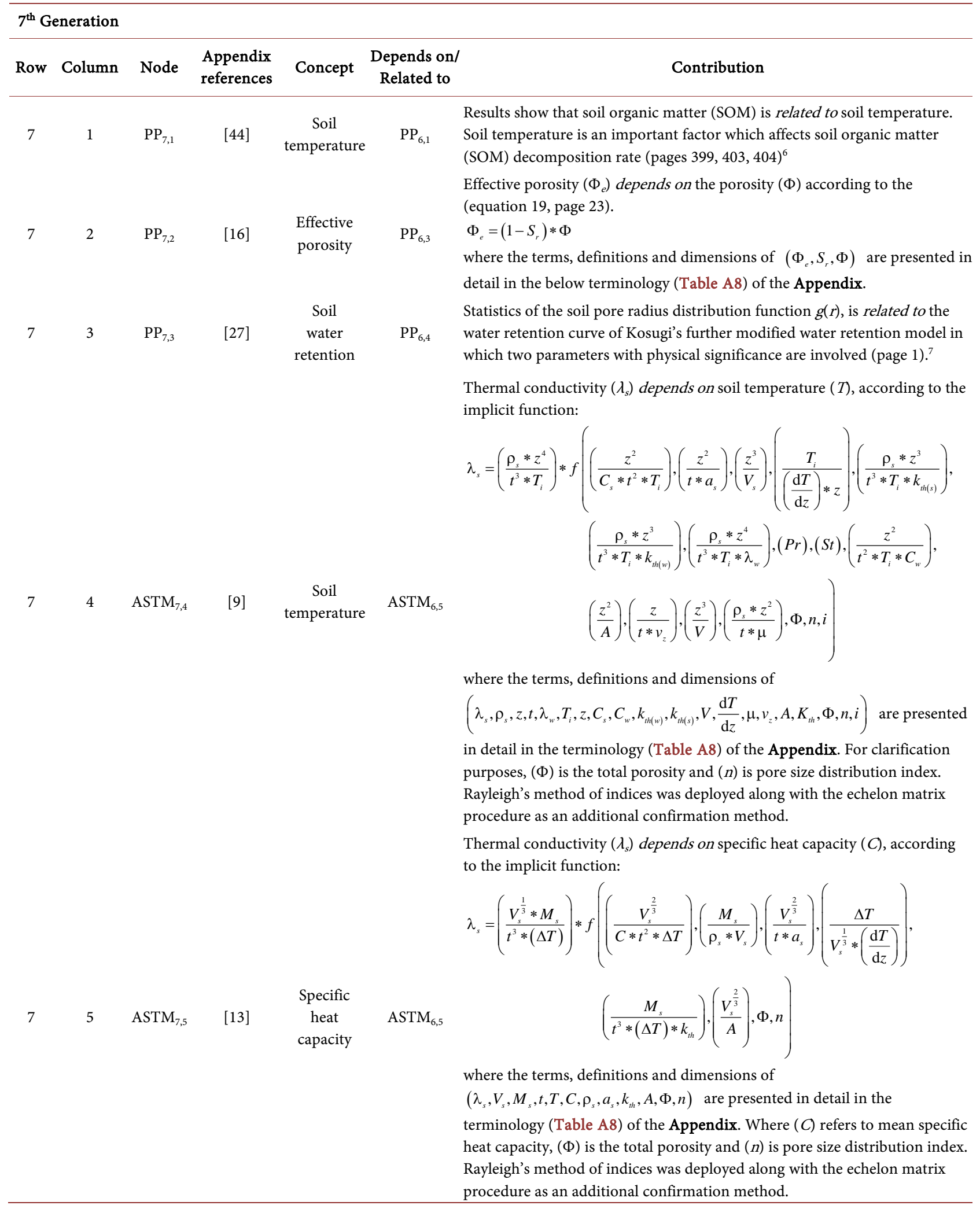

${ }^{4} \mathrm{No}$ model/function or quantitative path exists, interconnecting the concepts.

${ }^{5}$ No model/function or quantitative path exists, interconnecting the concepts. 


\section{Continued}

\begin{tabular}{|c|c|c|c|c|c|c|}
\hline 7 & 6 & $\mathrm{PP}_{7,6}$ & [45] & $\begin{array}{c}\text { Ground } \\
\text { thermal/heat } \\
\text { flux }\end{array}$ & $\operatorname{ASTM}_{6,6}$ & $\begin{array}{l}\text { The heat transfer rate depends on ground heat/thermal flux }\left(G_{o}\right) \text {, according } \\
\text { to the equation 1, page } 214 \text { : } \\
R_{n}=H+L E+G_{o} \\
\text { where the terms, definitions and dimensions of }\left(R_{n}, H, L E, G_{o}\right) \text { are } \\
\text { presented in detail in the below terminology (Table A8) of the Appendix. }\end{array}$ \\
\hline
\end{tabular}

\section{Terminology Table-SI Units}

Table A8. All the term and the soil/water physicochemical \& biological properties that are being used in the above Appendix tables, including their symbols and dimensions.

Parent material defined as the reference to unconsolidated mass from which the solum is developed by pedogenic processes (soil survey manual)

Particle size distribution is the fractions of the various soil separates in a soil sample, often expressed as mass percentages.

Soil organic matter (SOM) is the organic matter component of soil, consisting of plant and animal detritus at various stages of decomposition, cells and tissues of soil microbes, and substances that soil microbes synthesize

Soil texture is a classification instrument used both in the field and laboratory to determine soil classes based on their physical texture

\section{Latin Symbols}

$(\mathcal{A})$ Permeability coefficient or gravity term defined ad hoc by (Jaynes \& Gifford, 1981) as given in [25]

(A) Constant defined ad hoc by Lassabatere et al., 2010, as given in [28]

(a) Parameter defined ad hoc by Van Genuchten, 1980 as given in [42], inverse of air entry pressure in soils

$\left(A_{\text {inf }}\right),(A)$ Cross section of the infiltrometer cylinder/control volume cross section

(B) Constant defined ad hoc by Lassabatere et al., 2010, as given in [28]

(b) Parameter defined ad hoc by Van Genuchten, 1980 as given in [42]

Biot number, where $B i=\frac{k_{t h(s)} * V_{s}}{\lambda_{s} * A}$ heat transfer phenomena dimensionless quantity

(C) Specific capacity in Richards' equation, as given in [37]

Specific heat capacity (mean) defined as the ability of a given substance's mass to store enthalpy while undergoing a given temperature change without undergoing a phase change. $\left.{ }_{s}\right)$ denotes the bulk soil and ${ }_{w}$ ) denotes 'as regards the water'

(c) Constant defined ad hoc by Brooks \& Corey, 1964 as given in [16]

(c) Parameter defined ad hoc by Van Genuchten, 1980 as given in [42]

(Ca) Capillary number, where $C a=\frac{\mu * v_{2}}{\gamma}$ (Schluberger Oil Field Glossary)

$\left(C_{i}\right) \quad$ Concentration molecular initial

Shear modulus/elastic tensor defined as the frequency-dependent elastic moduli by which a compressible viscous fluid is characterized

Diffusivity/Hydraulic diffusivity defined as the ratio of transmissivity divided by the storage coefficient (storativity) or the hydraulic conductivity divided by the specific storage (Lohman, 1972) as given in [31] and (United States Geological Survey-USGS, Glossary of Hydrologic Terms), as given in [50]

$\left(D_{t h}\right) \quad$ See thermal diffusivity

$\left(\frac{\mathrm{d} C_{i}}{\mathrm{dt}}\right)$ Chemical reaction rate defined as the speed at which reactants are converted into products 


\section{Continued}

$\left(d_{\text {grain }}\right) \quad$ Mean soil grain diameter defined as the average estimated value of the grained soil diameter

$\left(d_{\text {inner }}\right) \quad$ Diameter of the inner ring of a double ring infiltrometer

$\left(d_{\text {pore }}\right) \quad$ Diameter mean pore size

$\left(d_{\text {ring }}\right) \quad$ Diameter of the ring of the infiltrometer

$\left(\frac{\mathrm{d} T}{\mathrm{~d} z}\right) \quad$ Temperature/thermal gradient vertical direction, within boundaries

$\left[\mathrm{L}^{-1} \cdot \Theta\right]$

$f(r) \quad$ Volume frequency defined ad hoc by Pereira \& Arson, 2017 as given in [35]

Gravitational acceleration/gravitational constant defined as the acceleration on an object caused by the force of gravitation

$\left(G_{o}\right)$ Ground heat flux defined as energy received by the soil to heat it per unit of surface and time

$g(r) \quad$ Pore radius distribution function by Kosugi, 1997, as given in [27]

Sensible heat (flux) defined as the energy moving from one system to another that changes its temperature rather than changing its phase

(H) Head of ponding defined as the depth of the ponded water above the surface

Soil water pressure head/Hydrostatic pressure defined by the hydrostatic pressure expressed as the height of a column of water that the pressure can support at the point of measurement United States Geological Survey-USGS, Glossary of Hydrologic Terms, given in [50]. Hydrostatic pressure is the pressure exerted by the weight of water at any given point in a body of water at rest (American Geosciences Institute-AGI, Glossary of Geology), given in [48]. See also matric suction

Capillary pressure head defined as the pressure difference between a fluid of a higher pressure and another fluid of a lower. It is common practice to express the pressure as an equivalent of a water height Encyclopedia of Soil Science

Capillary (entry) pressure head defined as the pressure (in column height) to enter the non-wetting phase to the

Hydraulic gradient/Darcy slope defined as the inclination of the line joining different pressure heads. A line joining the points of highest elevation of water in a series of vertical open pipes rising from a pipeline in which water flows under pressure (ASCE)

Capillary pressure function defined ad hoc by (Leverett, 1941) as the relationship between the capillary pressure and the pore structure, as given in [29]

Hydraulic conductivity/Coefficient of permeability defined as a proportionality constant (in Darcy's Law), relating hydraulic gradient to specific discharge which for an isotropic medium and homogeneous fluid, equals the volume of water at the existing kinematic viscosity that will move in unit time under a unit hydraulic gradient through a unit area measured at right angles to the direction of flow

Intrinsic permeability/absolute permeability/specific permeability defined as the measure of the relative ease with which a porous medium can transmit a fluid under a potential gradient and is a property of the medium alone Lohman, 1972, as given in [31] and United States Geological Survey-USGS, Glossary of Hydrologic Terms, given in [50] the measurement of the permeability, or ability to flow or transmit fluids through a rock, conducted when a single fluid, or phase, is present in the rock Schluberger Oil Field Glossary, as given in [49]

Initial unsaturated hydraulic conductivity defined as a quantitative measure of an unsaturated soil's ability to transmit water when subjected to a hydraulic gradient at the initial stage of wetting

Relative hydraulic conductivity defined ad hoc by Mualem's 1976 as given in [32], by the given equation $\left(K_{r}\right)=$ $\left(\theta-\theta_{r}\right) /\left(\theta_{s}-\theta_{r}\right)$

Fluid solubility defined as the property of a fluid substance called solute to dissolve in a solid, liquid or gaseous solvent

Saturated hydraulic conductivity defined as a quantitative measure of a saturated soil's ability to transmit water when subjected to a hydraulic gradient or the easiness with which pores of a saturated soil permit water movement. 


\section{Continued}

$\left(k_{t h}\right),\left(k_{t h(s)}\right)$ Heat transfer coefficient/coefficient of convection the proportionality constant between the heat flux and the

$\left(k_{t h(w)}\right)$, thermodynamic driving force for the flow of heat (i.e., the temperature difference, $\left.\left.\Delta T\right) .{ }_{s}\right)$ denotes the coefficient of $\left[\mathrm{M} \cdot \mathrm{T}^{-2.5} \cdot \Theta^{-1}\right]$ the bulk soil and $\left({ }_{w}\right)$ denotes "as regards the water"

Pore connectivity empirical parameter of Mualem's equation with the value 0.5 commonly used defined ad hoc by Di Prima, 2016 as given in [20] and by (Oh et al., 2015) as given in [34]

Latent heat defined as the flux of heat from the Earth's surface to the atmosphere and is associated with evaporation or transpiration

(M) Initial liquid mass defined as the mass of our interest before the progress of a physical phenomenon

$\left(M_{s}\right) \quad$ Soil mass/Mass of the bulk soil of our interest (control mass)

(m) Parameter defined ad hoc by (Liu, et al., 2014) as given in [30]

Calculated value defined ad hoc by Di Prima, 2016 as the equal of the numerical quantity 1-(1/n) as given in [20], (eq. 15b)

(n) Shape parameter defined ad hoc by Xu et al., 2012 as given in [46]

(n) Pore size distribution index defined ad hoc by Mualem, 1976 \& Van Genuchten, 1980 as given in [32] \& [42]

(n) Parameter defined ad hoc by Liu, et al., 2014 as given in [30]

Matric suction defined ad hoc by Oh et al., 2015 as the pressure difference between the air and the water in soil pores [34]

Capillary pressure defined as the difference in pressure across the interface between two immiscible fluid phases

$\left(P_{c}\right) \quad$ jointly occupying the interstices of a porous medium caused by interfacial tension between the two phases American Geosciences Institute-AGI, Glossary of Geology, as given in [48]

$q(t),(q)$ Infiltration rate defined as the volume flux of water entering through a unit soil surface area. Alternative symbols $(f), i(t)$

$\left(q_{H}\right) \quad$ Heat flux/heat transfer rate defined ad hoc by Wang \& Bou-Zeid, 2012, as given in [45]

( $r$ ) Average pore space defined as the average space diameter among soil particles

( $r$ ) Radius of natural pores defined as the radius of, for simplicity purposes, spherical shaped pores

Reynolds number, where $R e=\frac{\rho_{w} * V_{z} * Z}{\mu}$ introduced by Sommerfeld, 1909, as given in [40]

Richardson number, where $R i=\frac{g * z}{v_{z}^{2}}$ dimensionless quantity in fluid mechanics

$\left(R_{n}\right) \quad$ Net radiation see Heat flux/heat transfer rate/defined as the radiative flux transported towards the earth's surface

(s) Liquid saturation defined as the volume of the liquid phase per unit void volume in the packed column

Sorptivity/soil sorptivity defined ad hoc by Philips, 1957 as the measure of the capacity of the medium to absorb or desorb liquid by capillarity, as given in [36]

(Sc) Schmidt number, where $S c=\frac{\mu}{\rho * D}$ dimensionless quantity in fluids mechanics

Effective saturation/Degree of saturation/Percent saturation/Normalize water content terms used equally,

$\left(S_{e}\right) \quad$ defined as the ratio expressed as a percentage of the volume of water to the total volume of intergranular space (voids) in a given porous medium regarding Van Genuchten, 1980, as given in [42]. Alternative symbol $(\Theta)$

$\left(S_{o}\right) \quad$ Sorptivity in state $\left({ }_{o}\right)$ as regards Haverkamp, 1994 equation, as given in [24]

(Sh) Sherwood number, where $S h=\frac{K * Z}{D}$ dimensionless quantity in diffusion mass transport

Maximum Sorptivity defined as the maximum capacity of a medium (dry state) to absorb or desorb liquid by capillarity 


\section{Continued}

$\left(S_{r}\right) \quad$ Residual saturation defined ad hoc by Brooks \& Corey, 1964 as given in [16]

( $t$ Time elapsed

$\left(t_{f}\right) \quad$ Time at the final stage of percolation

(T), $\left(T_{i}\right)$ Temperature, $\left({ }_{i}\right)$ denotes the initial phase

$\left(t_{i}\right) \quad$ Time at the initial stage of percolation

$\left(t_{p}\right) \quad$ Time at the beginning of the ponding stage of percolation

(z) Percolation depth (vertical)/wetting front/heat transfer length (vertical)/membranes penetration depth

(V) Water volume

$\left(V_{s}\right) \quad$ Volume of the bulk soil or massive soil (control volume)

$\left(v_{z}\right) \quad$ Vertical percolation velocity defined as the percolation that occurs in the vertical direction

(z) Vertical distance/penetration depth/wetting depth/penetration depth at saturation state

\section{Greek Symbols}

(a) Parameter defined ad hoc by Van Genuchten, 1980 as given in [42] as the reciprocal of capillary pressure

(a) Total porosity also given as $(\Phi)$, the complement of the ratio $\left(\rho_{s} / \rho_{p}\right)$.

$(\alpha),\left(a_{s}\right),\left(a_{n}\right)$ Thermal diffusivity defined as the ratio of the thermal conductivity to the volumetric heat capacity. Where $\left({ }_{s}\right)$

denotes the bulk soil and $\left(_{w}\right)$ denotes "as regards the water". It has the SI derived unit of $\left(\mathrm{m}^{2} \cdot \mathrm{s}^{-1}\right)$.

$\left(\beta_{o}\right) \quad$ Brutsaert equation parameter defined ad hoc by Brutsaert [17], as given in Assouline, 2013, as given in [15]

Shape constant in Haverkamp, 1994 equation, as given in [24]

$(\gamma)$

Vapour-liquid/Interfacial tension/Surface tension defined as the elastic tendency of a fluid surface which makes it acquire the least surface area possible Speight, 2020, as given in [41]

( $\gamma$ ) Proportionality constant in Haverkamp, 1994 equation, as given in [24]

$(\Delta T) \quad$ Initial temperature difference

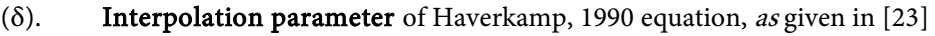

( $\eta$ Dynamic or absolute viscosity defined as a measure of water's internal resistance

$(\Theta)$ Degree of saturation (see also effective saturation)

Moisture content/soil-water content/water retention defined as the ratio of the mass of water contained in the

$(\theta)$ pore spaces of soil or rock material, to the solid mass of particles in that material, expressed as a percentage ASTM D653-20, given in [4]

$\left(\theta_{i}\right) \quad$ Initial moisture content defined as the moisture volume percentage in soils before irrigation or raining

$\left(\theta_{m}\right) \quad$ Maximum moisture content defined as the maximum value of the liquid content as given above

$\left(\theta_{o}\right),\left(\theta_{n}\right)$ Volumetric water content in final \& initial states according to Haverkamp, 1994 equation, as given in [24]

$\left(\theta_{r}\right) \quad$ Residual moisture content is the quantity of water retained in a residual soil (as percent)

$\left(\theta_{s}\right) \quad$ Saturated moisture content defined as the liquid content value in a saturated soil

Thermal conductivity defined as the proportionality factor in Fourier's Law that represents the ability of soil to conduct heat and is equivalent to the thermal flux per unit temperature gradient. In SI units, thermal conductivity is measured in watts per meter-kelvin $\left(\mathrm{W} \cdot \mathrm{m}^{-1} \cdot \mathrm{K}^{-1}\right)$. Thermal conductivity often denoted, $\lambda$, or $\left.\kappa\right)$. $(\lambda)$ is referring to the liquid of our interest.

$\left(\lambda_{s}\right) \quad$ Thermal conductivity where $\left({ }_{s}\right)$ denotes the bulk soil 


\section{Continued}

$\left(\lambda_{w}\right) \quad$ Thermal conductivity where $\left({ }_{w}\right)$ denotes the water phase

$\left[\mathrm{M} \cdot \mathrm{L} \cdot \mathrm{T}^{-3} \cdot \Theta^{-1}\right]$

( $\mu$ ) See Dynamic or absolute viscosity

$\left[\mathrm{M} \cdot \mathrm{L}^{-1} \cdot \mathrm{T}^{-1}\right]$

( $\rho$ Liquid's density defined as a liquid is its mass per unit volume

$\left(\rho_{p}\right) \quad$ Soil mass density or particle density

Soil bulk density/average bulk density defined as for mostly powders and granules, the mass of many particles of the material divided by the total volume they occupy/the average density value of the control volume material

$\left(\rho_{w}\right) \quad$ Water density defined as water is its mass per unit volume

Vapour-liquid Interfacial tension/Surface tension defined as the elastic tendency of a fluid surface which makes it acquire the least surface area possible

(Ф) Total porosity also given as $(\mathbf{a})$

$(\varphi)$ Average contact angle of the liquid-air interface

$\left(\Phi_{e}\right) \quad$ Effective porosity defined as the ratio of the volume of the voids of a soil or rock mass that can be drained by gravity to the total volume of the mass (ASTM D653-20), as given in [4]

Soil water potential/water potential defined as the quantification of the tendency of water to move from one area to another due to osmosis, gravity, mechanical pressure or matrix effects such as capillary action (which is caused by surface tension)

Matric pressure/matric potential at the wetting front defined as the difference between the applied air pressure and

$\left(\psi_{f}\right) \quad$ the water pressure. The pressure of the water in a pore of the medium relative to the pressure of the air United States Geological Survey-USGS, Glossary of Hydrologic Terms, as given in [50]

\section{Appendix References}

\section{ASTM Standards}

[1] ASTM C714-17, Standard Test Method for Thermal Diffusivity of Carbon and Graphite by Thermal Pulse Method.

[2] ASTM C1585-20, Standard Test Method for Measurement of Rate of Absorption of Water by Hydraulic-Cement Concretes.

[3] ASTM C1792-14, Standard Test Method for Measurement of Mass Loss versus Time for One-Dimensional Drying of Saturated Concretes.

[4] ASTM D653-20, Standard Terminology Relating to Soil, Rock, and Contained Fluids.

[5] ASTM D3385-18, Standard Test Method for Infiltration Rate of Soils in Field Using Double-Ring Infiltrometer.

[6] ASTM D4612-16, Standard Test Method for Calculating Thermal Diffusivity of Rock and Soil.

[7] ASTM D5093-15e1, Standard Test Method for Field Measurement of Infiltration Rate Using Double-Ring Infiltrometer with Sealed-Inner Ring.

[8] ASTM D5126-16e1, Standard Guide for Comparison of Field Methods for Determining Hydraulic Conductivity in Vadose Zone.

[9] ASTM D5334-14, Standard Test Method for Determination of Thermal Conductivity of Soil and Soft Rock by Thermal Needle Probe Procedure.

[10] ASTM D5856-15, Standard Test Method for Measurement of Hydraulic Conductivity of Porous Material Using a Rigid-Wall, Compaction-Mold Permeameter. 
[11] ASTM D7100-11 (2020) Standard Test Method for Hydraulic Conductivity Compatibility Testing of Soils with Aqueous Solutions.

[12] ASTM E1461-13, Standard Test Method for Thermal Diffusivity by the Flash Method.

[13] ASTM E2585-09 (2015) Standard Practice for Thermal Diffusivity by the Flash Method.

[14] ASTM F316-03 (2019) Standard Test Methods for Pore Size Characteristics of Membrane Filters by Bubble Point and Mean Flow Pore Test.

\section{Scientific published papers}

[15] Assouline, S. (2013) Infiltration into Soils: Conceptual Approaches and Solutions. Water Resources Research, 49, 1755-1772. https://doi.org/10.1002/wrcr.20155

[16] Brooks, R.H. and Corey, A.T. (1964) Hydraulic Properties of Porous Media. Hydrology Papers, Colorado State University, Fort Collins.

[17] Brutsaert, W. (1977) Vertical Infiltration in Dry Soil. Water Resources Research, 13, 363-368. https://doi.org/10.1029/WR013i002p00363

[18] Camara, J., et al. (2017) Lithologic Control on Soil Texture Heterogeneity. Geoderma, 287, 157-163. https://doi.org/10.1016/j.geoderma.2016.09.006

[19] Culligan, P.J., et al. (2005) Sorptivity and Liquid Infiltration into Dry Soil. Advances in Water Resources, 28, 1010-1020. https://doi.org/10.1016/j.advwatres.2005.04.003

[20] Di Prima, S. (2016) Testing a New Automated Single Ring Infiltrometer for Beerkan Infiltration Experiments. Geoderma, 262, 20-34. https://doi.org/10.1016/j.geoderma.2015.08.006

[21] Drotz, S.H., et al. (2010) Effects of Soil Organic Matter Composition on Unfrozen Water Content and Heterotrophic CO2 Production of Frozen Soils. Geochimica et Cosmochimica Acta, 74, 2281-2290. https://doi.org/10.1016/j.gca.2010.01.026

[22] Fu, W.S. and Shieh, W.J. (1990) A Transient Natural Convection in a Uniformly Heated Enclosure under Time-Dependent Gravitational Acceleration Field. International Communications in Heat and Mass Transfer, 17, 501-510. https://doi.org/10.1016/0735-1933(90)90068-U

[23] Haverkamp, R., Parlange, J.Y., Starr, Y.L., Schmitz, G. and Fuentes, C. (1990) Infiltration under Ponded Conditions. 3. A Predictive Equation Based on Physical Parameters. Soil Science, 149, 292-300. https://doi.org/10.1097/00010694-199005000-00006

[24] Haverkamp, R., Ross, P.J., Smetten, K.R.J and Parlange, J.Y. (1994) Three-Dimensional Analysis of Infiltration from the Disc Infiltrometer: 2. Physically Based Infiltration Equation. Water Resources Research, 30, 2931-2935. https://doi.org/10.1029/94WR01788

[25] Jaynes, R.A. and Gifford, G.F. (1981) An In-Depth Examination of the Philip Equation for Cataloging Infiltration Characteristics in Rangeland Environments. Journal of Range Management, 34, 285-296. https://doi.org/10.2307/3897853

[26] Jindaluang, W., et al. (2013) Influence of Soil Texture and Mineralogy on Organic Matter Content and Composition in Physically Separated Fractions Soils of Thailand. Geoderma, 195-196, 207-219. https://doi.org/10.1016/j.geoderma.2012.12.003

[27] Kosugi, K. (1997) A New Model to Analyze Water Retention Characteristics of Forest Soils Based on Soil Pore Radius Distribution. Journal of Forest Research, 2, 1-8. https://doi.org/10.1007/BF02348255

[28] Lassabatere, L., et al. (2010) Effect of the Settlement of Sediments on Water Infiltra- 
tion in Two Urban Infiltration Basins. Geoderma, 156, 316-325. https://doi.org/10.1016/j.geoderma.2010.02.031

[29] Leverett, M.C. (1941) Capillary Behavior in Porous Solids. Transactions of the AIME, 142, 159-172. https://doi.org/10.2118/941152-G

[30] Liu, Y., et al. (2014) Effects of Capillary Pressure-Fluid Saturation-Relative Permeability Relationships on Predicting Carbon Dioxide Migration during Injection into Saline Aquifers. Energy Procedia, 63, 3616-3631. https://doi.org/10.1016/j.egypro.2014.11.392

[31] Lohman, S.W. (1972) Ground-Water Hydraulics. U.S. Geological Survey, Report: viii, 70 p., 9 Plates.

[32] Mualem, Y. (1976) A New Model for Predicting the Hydraulic Conductivity of Unsaturated Porous Media. Water Resources Research, 12, 513-522. https://doi.org/10.1029/WR012i003p00513

[33] Nimmo, J.R. (2004) Porosity and Pore Size Distribution. In: Encyclopedia of Soils in the Environment, Elsevier, London, Vol. 3, 295-303. https://doi.org/10.1016/B0-12-348530-4/00404-5

[34] Oh, S., et al. (2015) A Modified van Genuchten-Mualem Model of Hydraulic Conductivity in Korean Residual Soils. Water, 7, 5487-5502. https://doi.org/10.3390/w7105487

[35] Pereira, J.M. and Arson, C. (2013) Retention and Permeability Properties of Damaged Porous Rocks. Computers and Geotechnics, 48, 272-282. https://doi.org/10.1016/j.compgeo.2012.08.003

[36] Philips, J.R. (1957) The Theory of Infiltration: 4. Sorptivity and Algebraic Infiltration Equations. Soil Science, 84, 257-264. https://doi.org/10.1097/00010694-195709000-00010

[37] Richards, L.A. (1931) Capillary Conduction of Liquids through Porous Mediums. Physics, 1, 318-333. https://doi.org/10.1063/1.1745010

[38] Saenger, E.H., et al. (2011) Digital Rock Physics: Effect of Fluid Viscosity on Effective Elastic Properties. Journal of Applied Geophysics, 74, 236-241. https://doi.org/10.1016/j.jappgeo.2011.06.001

[39] Scheidegger, A.E. (1957) The Physics of Flow through Porous Media. 3rd Edition, University of Toronto Press, Toronto. https://doi.org/10.3138/9781487583750

[40] Sommerfeld, A. (1909) Ein Beitrag zur hydrodynamischen Erklärung der turbulenten Flüssigkeitsbewegungen (A Contribution to Hydrodynamic Explanation of Turbulent Fluid Motions). International Congress of Mathematicians, Vol. 3, 116-124.

https://docplayer.org/65491852-A-sommerfeld-ein-beitrag-zur-hydrodynamischender-turbulenten-fluessigkeitsbeweguengen-uebersicht-ueber-die-litteratur-des-gege nstandes.html

[41] Speight, G.J. (2020) Natural Water Remediation, Chemistry and Technology. https://doi.org/10.1016/B978-0-12-803810-9.00003-6

[42] Van Genuchten, M.T. (1980) A Closed-Form Equation for Predicting the Hydraulic Conductivity of Unsaturated Soils. Soil Science Society of America Journal, 44, 892-898. https://doi.org/10.2136/sssaj1980.03615995004400050002x

[43] Vereecken, H. (1995) Estimating the Unsaturated Hydraulic Conductivity from Theoretical Models Using Simple Soil Properties. Geoderma, 65, 81-92. https://doi.org/10.1016/0016-7061(95)92543-X

[44] Wang, D., et al. (2016) Effects of Temperature and Moisture on Soil Organic Matter 
Decomposition along Elevation Gradients on the Changbai Mountains, Northeast China. Pedosphere, 26, 399-407. https://doi.org/10.1016/S1002-0160(15)60052-2

[45] Wang, Z.H. and Bou-Zeid, E. (2012) A Novel Approach for the Estimation of Soil Ground Heat Flux. Agricultural and Forest Meteorology, 154-155, 214-221. https://doi.org/10.1016/j.agrformet.2011.12.001

[46] Xu, X., et al. (2012) Analysis of Single-Ring Infiltrometer Data for Soil Hydraulic Properties Estimation: Comparison of BEST and Wu Methods. Agricultural Water Management, 107, 34-41. https://doi.org/10.1016/j.agwat.2012.01.004

[47] Yang, F., et al. (2014) Organic Matter Controls of Soil Water Retention in an Alpine Grassland and Its Significance for Hydrological Processes. Journal of Hydrology, 519, 3086-3093. https://doi.org/10.1016/j.jhydrol.2014.10.054

\section{Glossary and Terms}

[48] American Geosciences Institute AGI (2020) Glossary of Geology. Fifth Edition, Revised. https://www.americangeosciences.org/pubs/glossary

[49] Schluberger Oil Field (2020) The Oilfield Glossary. https://www.glossary.oilfield.slb.com

[50] United States Geological Survey USGS (2020) Glossary of Hydrologic Terms. https://or.water.usgs.gov/projs_dir/willgw/glossary.html 